\title{
POTENCIAL EROSIVO DA CHUVA NO VALE DO RIO DOCE, REGIÃO CENTRO- LESTE DO ESTADO DE MINAS GERAIS - PRIMEIRA APROXIMAÇÃO ${ }^{1}$
}

\author{
Erosive potential of rainfall at Rio Doce Valley, central-east region of Minas Gerais state - first approach
}

Flávio Pereira de Oliveira², Marx Leandro Naves Silva ${ }^{3}$, Nilton Curi ${ }^{3}$,Mayesse Aparecida da Silva4, Carlos Rogério de Mello

\section{RESUMO}

Entre os fatores climáticos que interferem na erosão hídrica, a precipitação pluvial, expressa pela erosividade da chuva, é o de maior importância. Portanto, seu conhecimento torna-se fundamental na recomendação de práticas de manejo e conservação do solo que visem à redução da erosão hídrica. Nesse contexto, os objetivos deste trabalho foram: a) determinar a erosividade da chuva e sua distribuição, na região do Vale do Rio Doce, $\mathrm{MG}$, para nove sub-regiões; b) estimar o índice $\mathrm{EI}_{30}$ mensal, no período de 1969 a 2005, para os municípios de Ferros e Guanhães e c) determinar o tempo de retorno dos índices mensais e anuais de erosividade. $\mathrm{O}$ valor médio de erosividade obtido foi de $12.913 \mathrm{MJ} \mathrm{mm} \mathrm{ha}^{-1} \mathrm{~h}^{-1}$ ano $^{-1}$, sendo classificado como muito alto. Entre as sub-regiões, os valores de erosividade variaram de 8.243 a $26.676 \mathrm{MJ} \mathrm{mm} \mathrm{ha}^{-1} \mathrm{~h}^{-1}$ ano $^{-1}$. O período crítico em relação à erosão hídrica, em razão da ocorrência de chuvas erosivas, é de janeiro-março e novembro-dezembro, contribuindo com $88,6 \%$ da erosividade anual. De abril a outubro, praticamente inexiste a ocorrência de erosividade crítica. Os valores máximos individuais estimados para os tempos de retorno de 1, 10, 50 e 150 anos foram de 5.508, 15.534, 18.110, 19.632 e 5.542, 17.653, 20.954, $22.931 \mathrm{MJ} \mathrm{mm} \mathrm{ha}^{-1} \mathrm{~h}^{-1}$ ano $^{-1}$, para Ferros e Guanhães, respectivamente. A determinação dos valores de erosividade ao longo do ano permite identificar os meses nos quais os riscos de perdas de solo e água são mais elevados, o que exerce relevante papel no planejamento das práticas conservacionistas.

Termos para indexação: Erosividade, planejamento conservacionista, coeficiente da chuva, período de retorno da chuva.

\section{ABSTRACT}

Among the climatic factors that interfere in water erosion, precipitation, expressed by the rainfall erosivity, is of great importance. Therefore, its knowledge becomes fundamental for the recommendation for soil management and conservation practices that seek the reduction of water erosion. In that context, the objectives of this work were: a) to determine the rainfall erosivity and its distribution at Rio Doce Valley, Minas Gerais State, for nine sub-regions, b) to estimate the monthly EI index in the period from 1969 to 2005 for Ferros and Guanhães counties, and c) to determine the return periods of the monthly and yearly erosivity indexes. The average erosivity value obtained was $12.913 \mathrm{MJ} \mathrm{mm} \mathrm{ha}^{-1} \mathrm{~h}^{-1}$ year-1, being classified as very high. Among the sub-regions, the erosivity values varied from 8.243 to $26.676 \mathrm{MJ} \mathrm{mm} \mathrm{ha}^{-1} \mathrm{~h}^{-1}$ year-1. The critical periods in relation to water erosion due to the occurrence of erosive rains are January-March and November-December, contributing with $88.6 \%$ of the annual erosivity. From April to October, the occurrence of critical erosivity practically does not exist. The estimated individual maximum values for the return periods of $1,10,50$, and 150 years were of 5.508, 15.534, 18.110, 19.632, and 5.542, 17.653, 20.954, $22.931 \mathrm{MJ} \mathrm{mm} \mathrm{ha}^{-1} \mathrm{~h}^{-1} \mathrm{year}^{-}$ ${ }^{1}$ for Ferros and Guanhães, respectively. The determination of the erosivity values throughout the year allows to identify the months in which the risks of soil and water losses are higher, which is important for planning the conservation practices.

Index terms: Erosivity, conservation planning, rainfall coefficient, rainfall return period.

\section{(Recebido em 5 de junho de 2006 e aprovado em 12 de janeiro de 2009)}

\section{INTRODUÇÃO}

Fundamentalmente, a erosividade, definida como o potencial da chuva em causar a desagregação e o transporte das partículas do solo, depende de suas características físicas básicas, a saber: tamanho, forma e velocidade terminal de queda das gotas. Combinadamente, essas características determinam a energia cinética total da chuva (Moreti et al., 2003). A resistência dos solos a erosão hídrica apresenta grande amplitude devido à variabilidade climática que influi na erosividade das chuvas (Carvalho et al., 2007).

De acordo com Wischmeier \& Smith (1958), para regiões de clima temperado, a melhor variável para avaliar a erosividade é o produto da energia cinética (E) e sua intensidade máxima em 30 minutos $\left(\mathrm{I}_{30}\right)$, expressa como índice $\mathrm{EI}_{30}$. Para regiões de clima tropical e subtropical, o modelo desenvolvido por Wischmeier \& Smith (1958) subestima a energia cinética das chuvas, pois não leva em conta a velocidade dos ventos, a distribuição de gotas de

'Parte da Dissertação de Mestrado do primeiro autor - Departamento de Ciência do Solo - Universidade Federal de Lavras/UFLA.

2Doutorando do Programa de Pós-Graduação em Ciência do Solo, Departamento de Solos - Universidade Federal do Rio Grande do Sul - DS/UFRGS - Av. Bento Gonçalves 7712 - Cx. P. 15100 - 91501-970 Porto Alegre, RS - Bolsista do CNPq - flavio solos@yahoo.com.br

3Professor do Departamento de Ciência do Solo - Universidade Federal de Lavras/UFLA - Cx. P. 3037 - 37.200-000 - Lavras, MG - marx@dcs.ufla.br, niltcuri@dcs.ufla.br

${ }^{4}$ Engenheira Florestal - Departamento de Solos e Nutrição de Plantas - Universidade Federal de Lavras/UFLA - Cx. P. 3037 - $37.200-000$ - Lavras, MG mayesse@gmail.com

${ }_{5}^{5}$ Professor do Departamento de Engenharia Agrícola - Universidade Federal de Lavras/UFLA - Cx. P. 3037 - 37.200-000 - Lavras, MG - rog.mello@terra.com.br 
diferentes tamanhos nem as elevadas intensidades das chuvas (Lal, 1976). Mesmo assim, o índice $\mathrm{EI}_{30}$ vem sendo utilizado praticamente em todo o Brasil, principalmente como parâmetro para avaliar a erosividade e na obtenção de linhas isoerosivas (Dedecek, 1988).

Nas condições tropicais do Zimbabwe, Hudson (1971) observou que as chuvas só tornavam-se erosivas quando sua intensidade superava $25 \mathrm{~mm} \mathrm{~h}^{-1}$, o que o levou a propor um índice que é a soma das energias cinéticas das chuvas com intensidade maior do que $25 \mathrm{~mm} \mathrm{~h}^{-1}$ (KE>25). Lal (1988) verificou que para chuvas tropicais de alta intensidade, nas condições da Nigéria, as melhores correlações com as perdas de solo se verificaram com os índices do tipo precipitação pluvial multiplicada pela intensidade máxima de qualquer período consecutivo, em minutos ( $\left.\mathrm{PI}_{\mathrm{m}}\right)$.

Marques et al. (1998) mencionaram que esse índice poderia se correlacionar melhor com as perdas por erosão, em regiões tropicais. Apesar desta consideração, possivelmente, a maior limitação de ambos os índices de erosividade é a não contemplação das condições de umidade antecedente do solo e do efeito erosivo do escoamento superficial sobre o mesmo.

Nos diversos estudos de determinação da erosividade média anual para diferentes regiões brasileiras, observa-se que a maioria dos valores encontrados se enquadra na faixa de 5.000 a $12.000 \mathrm{MJ} \mathrm{mm} \mathrm{ha}^{-1} \mathrm{~h}^{-1}$ que, normalmente, ocorrem no Brasil (Cogo, 1988). Mas, principalmente, os valores de erosividade média anual se enquadram melhor na faixa de variação de 3.116 a 20.035 MJ mm ha ${ }^{-1} \mathrm{~h}^{-1}$ encontrada por Silva (2004) por meio de mapa de erosividade da chuva para o Brasil.

O tempo de retorno é outro fator importante, definido como o intervalo médio de tempo em longo prazo ou o número de anos que separam um evento de dimensão conhecida de outro evento com dimensão igual ou superior, sendo, ao menos uma vez, em qualquer ano, seu valor igualado ou superado, constituindo um importante parâmetro da erosividade (Haan, 1979). Ele pode ser determinado por meio de distribuições de probabilidades, como Gumbel, Gama, Log-Normal 2 e 3 parâmetros e outros (Freitas et al., 2001). Estudos probabilísticos envolvendo climáticas como a precipitação foram realizados por Ribeiro et al. (2007) para a região de Barbacena, MG e Junqueira Junior et al. (2007) para a regiaõ do Alto Rio Grande, minicipio de Madre de Deus, MG. Assim, valores anuais e mensais de determinado evento aproximam-se de um padrão definido de distribuição de freqüência, quando o número de observações, em cada ano, torna-se o mais amplo possível (Schwab et al., 1966). No caso do planejamento de terraceamento agrícola (Schwab et al., 1966; Lombardi
Neto et al., 1989), tal evento hidrológico é calculado normalmente para um período de retorno de 10 a 15 anos.

Estudando padrões de chuva e variabilidade espacial da erosividade para o Sul de Minas Gerais, Aquino (2005) aplicou cinco distribuições de probabilidades para valores de erosividade, mensais e anuais, determinando o tempo de recorrência da erosividade. De acordo com os resultados, verificou-se que, dentre as distribuições estudadas, a Log-Normal apresentou maior precisão e que as erosividades anuais, para todos os tempos de recorrência, foram consideradas muito altas, segundo a classificação de Foster et al. (1981) modificada.

A região do Vale do rio Doce atualmente é das regiões mais degradadas pela erosão hídrica no estado de Minas Gerais. Ela sofreu um efeito antrópico muito impactante nos últimos 50 - 60 anos, que incluiu: uso indiscriminado do fogo nas pastagens de capim colonião que, naturalmente, já não oferecem uma boa cobertura ao terreno, total desrespeito à capacidade de suporte das pastagens, o que aliado ao relevo movimentado dominante e à ocorrência de chuvas erosivas concentradas resultou num quadro dramático de pobreza rural decorrente do processo de erosão acelerada, inclusive no topo dos morros (áreas de recarga do lençol freático), justificando estudos relativos a esses aspectos nessa região, visando a ações de planejamento de práticas de conservação do solo e da água.

Nesse contexto, conduziu-se este trabalho, com os objetivos de: a) determinar a erosividade da chuva e sua distribuição, na região do Vale do Rio Doce, MG, para nove sub-regiões; b) estimar o índice $\mathrm{EI}_{30}$ mensal, no período de 1969 a 2005, para os municípios de Ferros e Guanhães e c) determinar o tempo de retorno dos índices mensais e anuais de erosividade.

\section{MATERIALE MÉTODOS}

$\mathrm{O}$ estudo foi realizado em áreas experimentais de plantios de eucalipto da Celulose Nipo Brasileira S. A. (CENIBRA S. A.), localizadas em nove sub-regiões distintas (Alfié, Cataquinho, Cocais, Coqueiro, Cordeiros, Fábrica, Gaspar, Lagoa Grande e Rubro Negro), no Vale do Rio Doce, região Centro-Leste do estado de Minas Gerais (Tabela 1). Segundo Köeppen, os seguintes tipos climáticos podem ocorrer na área de estudo: Aw - clima tropical, com inverno seco e estação chuvosa no verão. A estação seca ocorre entre os meses de maio e setembro; Cwa - clima de inverno e verão chuvoso. A temperatura do mês mais frio é inferior a 18 ${ }^{\circ} \mathrm{C}$ e a do mais quente ultrapassa $22^{\circ} \mathrm{C}$. A estação seca ocorre entre os meses de abril e setembro; e Cwb - clima mesotérmico de inverno seco e verão fresco, com temperaturas abaixo de $22{ }^{\circ} \mathrm{C}$. Esse clima é característico de áreas de maior altitude (Celulose Nipo Brasileira - Cenibra, 2001). 
Tabela 1 - Algumas características ambientais das áreas experimentais.

\begin{tabular}{cccccc}
\hline Município & Sub-região & Latitude & Longitude & Altitude & Clima \\
\hline & & & & $\mathrm{m}$ & Köeppen \\
Sabinópolis & Lagoa Grande & $18^{\circ} 39^{\prime} 58^{\prime \prime} \mathrm{S}$ & $42^{\circ} 55^{\prime} 16^{\prime \prime} \mathrm{W}$ & 1.012 & Cwa \\
Peçanha & Cataquinho & $18^{\circ} 42^{\prime} 24^{\prime \prime} \mathrm{S}$ & $42^{\circ} 29^{\prime} 25^{\prime \prime} \mathrm{W}$ & 1.015 & $\mathrm{Cwa}$ \\
Antonio Dias & Cocais & $19^{\circ} 29^{\prime} 19^{\prime \prime} \mathrm{S}$ & $42^{\circ} 51^{\prime} 54^{\prime \prime} \mathrm{W}$ & 1.273 & $\mathrm{Cwb}$ \\
São Dom. Prata & Alfié & $19^{\circ} 46^{\prime} 28^{\prime \prime} \mathrm{S}$ & $42^{\circ} 54^{\prime} 24^{\prime \prime} \mathrm{W}$ & 1.143 & $\mathrm{Cwb}$ \\
Santa Bárbara & Gaspar & $19^{\circ} 59^{\prime} 00^{\prime \prime} \mathrm{S}$ & $43^{\circ} 18^{\prime} 19^{\prime \prime} \mathrm{W}$ & 847 & $\mathrm{Cwb}$ \\
Belo Oriente & Fábrica & $19^{\circ} 18^{\prime} 50^{\prime \prime} \mathrm{S}$ & $42^{\circ} 23^{\prime} 38^{\prime \prime} \mathrm{W}$ & 240 & $\mathrm{Aw}$ \\
Sto. Ant. do Itambé & Coqueiro & $18^{\circ} 33^{\prime} 17^{\prime \prime} \mathrm{S}$ & $43^{\circ} 10^{\prime} 13^{\prime \prime} \mathrm{W}$ & 993 & $\mathrm{Cwa}$ \\
Açucena & Rubro Negro & $19^{\circ} 02^{\prime} 25^{\prime \prime} \mathrm{S}$ & $42^{\circ} 25^{\prime} 48^{\prime \prime} \mathrm{W}$ & 800 & $\mathrm{Aw}$ \\
Caratinga & Cordeiros & $19^{\circ} 33^{\prime} 20^{\prime \prime} \mathrm{S}$ & $42^{\circ} 23^{\prime} 42^{\prime \prime} \mathrm{W}$ & 310 & $\mathrm{Aw}$ \\
\hline
\end{tabular}

Fonte: Cenibra (2004), com adaptações.

Os solos dominantes são os Latossolos, seguidos pelos Cambissolos, o relevo é principalmente ondulado e forte ondulado, a vegetação nativa é representada pela floresta subcaducifólia e o uso atual da terra é com pastagens e eucalipto (Cenibra, 2001).

Para o estudo, foram utilizados dados pluviométricos correspondentes ao ano de 2005, obtidos de estações climatológicas (Figura 1), distribuídas nos municípios e sub-regiões de abrangência do estudo (Tabela 1), que geraram dados a cada 5 minutos. A partir das precipitações, foram calculadas as energias cinéticas totais das chuvas para cada evento. Foram consideradas chuvas individuais aquelas separadas por mais de 6 horas. As chuvas menores que $10 \mathrm{~mm}$, com intensidade máxima menor que $24 \mathrm{~mm} \mathrm{~h}^{-1}$, em 15 minutos ou energia cinética menor que 3,6 MJ, foram consideradas não erosivas (Maria, 1994). Para o cálculo da energia cinética (Ec), utilizou-se a equação proposta por Wischmeier \& Smith (1958):

$$
E c=0,119+0,0873 \log I
$$

em que:

$\mathrm{Ec}=$ energia cinética $\left(\mathrm{MJ} \mathrm{ha}{ }^{-1} \mathrm{~mm}^{-1}\right)$; e I = intensidade média da chuva $\left(\mathrm{mm} \mathrm{h}^{-1}\right)$.

$\mathrm{O}$ índice de erosividade $\mathrm{EI}_{30}\left(\mathrm{MJ} \mathrm{mm} \mathrm{ha} \mathrm{m}^{-1} \mathrm{~h}^{-1}\right)$ de cada chuva individual erosiva foi calculado pela multiplicação da energia cinética pela sua intensidade máxima em 30 minutos $\left(\mathrm{mm} \mathrm{h}^{-1}\right)$. $\mathrm{O} \mathrm{EI}_{30}$ mensal foi calculado pelo somatório dos valores desse índice para todas as chuvas individuais erosivas que ocorreram em cada mês do ano e cuja soma, por sua vez, caracterizou o $\mathrm{EI}_{30}$ anual (Wischmeier \& Smith, 1958).
Foram acumulados os dados diários de precipitação pluvial do período compreendido entre 1969 e 2005, para Ferros e Guanhães, extraídos do banco de dados Hidroweb da Agência Nacional de Águas (ANA). A precipitação mensal foi constituída do somatório das precipitações diárias que ocorreram em determinado mês. Dessa forma, puderam ser obtidos os valores mensais da precipitação pluvial, para todos os meses de todos os anos da série.

Para se obter uma estimativa aproximada do índice de erosividade mensal, foi determinado o coeficiente da chuva, conforme proposto por Fournier (1956) e modificado por Lombardi Neto (1977):

$$
\mathrm{Rc}=\mathrm{p}^{2} \mathrm{P}^{-1}
$$

em que:

$\mathrm{Rc}=$ coeficiente de chuva $(\mathrm{mm}) ; \mathrm{p}=$ precipitação média mensal (mm); e P = precipitação média anual (mm).

Análises de regressão entre os valores do índice de erosividade $\mathrm{EI}_{30}$ mensal (variável dependente y), calculados com os dados pluviométricos obtidos das nove sub-regiões, e os valores do coeficiente de chuva (variável independente $\mathrm{x}$ ), determinados com dados do ano de 2005, permitiram obter a seguinte equação do tipo potencial, com seu respectivo coeficiente de correlação:

$$
E I_{30}=137,09(R c)^{0,7717} \quad \mathrm{R}^{2}=0,90
$$

Tal equação permitiu obter valores mensais do índice $\mathrm{EI}_{30}$ para as séries históricas de precipitação pluvial das regiões de Ferros e Guanhães.

Para verificar o tempo de retorno dos valores mensais e anuais de erosividade obtidos na série histórica das regiões estudadas, utilizou-se a distribuição Log-normal com 2 parâmetros. 


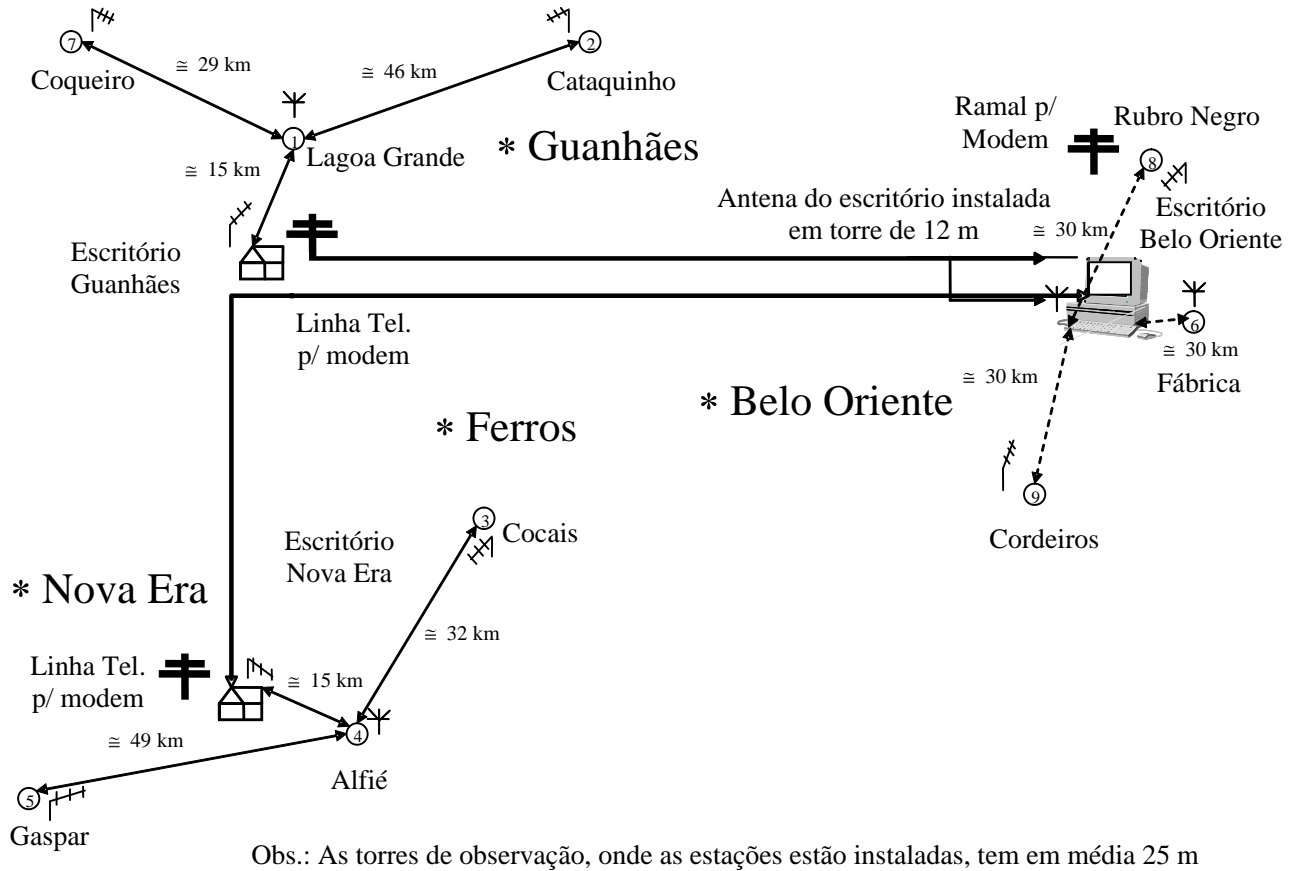

Figura 1 - Esquema de transmissão automática de dados climatológicos da área experimental (Cenibra, 2004).

A probabilidade, ou estimativa da frequência, foi obtida com base na equação geral de Chow (1954), que, na forma logarítmica, pode ser expressa como:

$$
\ln X_{T R}=\mu_{n}+K_{T R} \cdot \sigma_{n}
$$

Em que: $\mathrm{K}_{\mathrm{TR}}$, é a variável reduzida padronizada que, no caso desta distribuição, consiste nos valores de $\mathrm{z}$ da distribuição Normal (Haan, 1979). Os valores de cada erosividade associado à respectiva probabilidade de excedência podem ser obtidos por:

$$
X_{T R}=e^{\mu n+z \cdot \sigma_{n}}
$$

A frequência observada foi determinada por meio da seguinte fórmula:

$$
F_{o b s}=\frac{m}{(n+1)}
$$

em que:

$\mathrm{F}_{\mathrm{obs}}=$ frequência observada; $\mathrm{m}=$ ordem do valor da amostra ordenada; e $\mathrm{n}=$ tamanho da amostra.

O tempo de retorno (TR) pode ser estimado por:

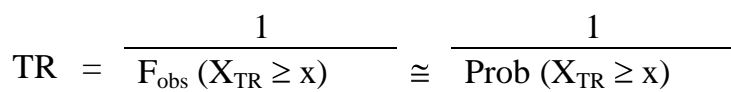

em que: TR é obtido em anos e Prob $\left(\mathrm{X}_{\mathrm{TR}} \geq \mathrm{x}\right)$ é a probabilidade de excedência, ou seja, do valor de $\mathrm{X}$ ser igualado ou superado.

\section{RESULTADOS E DISCUSSÃO}

A distribuição dos valores da precipitação pluvial e do índice de erosividade $\mathrm{EI}_{30}$, observados no ano de 2005, para as nove sub-regióes, pode ser verificado na Tabela 2. De acordo com a distribuição dos valores, verifica-se uma precipitação média anual de $1.564,5 \mathrm{~mm}$ para as regiões. Entre as sub-regiões, a precipitação anual variou de $1.284,1$ a $1.878,9 \mathrm{~mm}$, destacando-se Rubro Negro e Fábrica.

$\mathrm{Na}$ Tabela 3, podem ser verificadas as distribuições dos valores mensais da precipitação pluvial no período de estudo. Observa-se que os meses mais críticos estão compreendidos no período inicial (janeiro a março) e final (novembro e dezembro) de 2005, os quais contribuíram, em média, com $82,9 \%$ da precipitação anual. Resultados semelhantes foram observados por Val et al. (1986), para Lavras, MG, 
atualizados por Carvalho et al. (1989) e Aquino (2005), para Mococa, SP; Bertol (1993), para Lages, SC; Roque et al. (2001) para o município de Piraju, SP; e Martins (2005), para a região de Aracruz, ES.

Em relação ao índice de erosividade anual para as sub-regiões estudadas, verificou-se uma erosividade média de $12.913 \mathrm{MJ} \mathrm{mm} \mathrm{ha}^{-1} \mathrm{~h}^{-1}$ ano $^{-1}$. Entre as subregiões, a erosividade anual variou de 8.243 a $26.676 \mathrm{MJ}$ $\mathrm{mm} \mathrm{ha}{ }^{-1} \mathrm{~h}^{-1}$ ano $^{-1}$, destacando-se as regiões de Alfíe e Fábrica, respectivamente, com valores considerados muito altos, segundo a classificação de Foster et al. (1981) modificada.

$\mathrm{Na}$ Tabela 3, podem ser verificadas as distribuições dos valores mensais do índice de erosividade $\mathrm{EI}_{30}$, no período de estudo. Observa-se que meses considerados críticos contribuíram, em média, com $88,6 \%$ da erosividade anual. Por serem os meses de maiores precipitações o planejamento do manejo nos plantios, deve-se considerar que nesses meses podem ocorrer grandes perdas de solo e água em função dos elevados valores de erosividade da chuva e também da concentração de chuvas erosivas nesses períodos do ano. Segundo Bertoni \& Lombardi Neto (2005) a porcentagem do valor anual de EI que ocorre durante um período do ano quando o solo está sendo cultivado é bastante vulnerável à erosividade da chuva e difere significativamente de local para local.

Os valores de $\mathrm{EI}_{30}$ encontrados para as subregiões em estudo estão acima dos encontrados por vários pesquisadores (Carvalho et al., 1989; Bertol, 1993, 1994; Lopes \& Brito, 1993; Silva et al., 1997; Dias
\& Silva, 2003; Moreti et al., 2003; Silva \& Dias, 2003). Porém, o valor médio de erosividade se enquadra dentro da faixa de variação de 3.116 a $20.035 \mathrm{MJ} \mathrm{mm}$ $\mathrm{ha}^{-1} \mathrm{~h}^{-1}$ ano $^{-1}$, encontrada por Silva (2004) por meio de mapa de erosividade da chuva para o Brasil, e superior à faixa estabelecida para o país que é de 5.000 a 12.000 MJ mm ha ${ }^{-1} \mathrm{~h}^{-1}$ ano $^{-1}$, de acordo com estudos de Cogo (1988).

Os valores do índice $\mathrm{EI}_{30}$, mensal e anual estimados e o tempo de retorno para as regiões de Ferros e Guanhães, são mostrados na Tabela 4.

Observa-se que, para ambas as regiões estudadas, os valores máximos de erosividade mensal estão concentrados no período inicial (janeiro a março) e final (novembro e dezembro) do ano de 2005, principalmente para a região de Guanhães. Os valores mínimos estão concentrados no período de abril a outubro. Pode-se verificar também que, para os meses que apresentaram valores máximos, o tempo de retorno para as erosividades mensais consideradas críticas são acima de $500 \mathrm{MJ} \mathrm{mm} \mathrm{ha}^{-1} \mathrm{~h}^{-1} \mathrm{ano}^{-1}$, está entre 1,1 e 2 anos, para ambas as regiões. Já, para os meses que apresentaram valores mínimos de erosividade, o tempo de retorno variou entre os meses para cada região.

Em relação aos valores anuais de erosividade, verifica-se que, para ambas as regiões, as erosividades estimadas são consideradas altas. De acordo com Foster et al. (1981), erosividades anuais maiores que $8.000 \mathrm{MJ} \mathrm{mm} \mathrm{ha} \mathrm{h}^{-1} \mathrm{ano}^{-1}$ são consideradas muito altas.

Tabela 2 - Distribuição dos valores da precipitação pluvial e do índice de erosividade, $\mathrm{EI}_{30}$, observadas, no ano 2005 , em nove sub-regiões, na região do Vale do Rio Doce, MG.

\begin{tabular}{ccc}
\hline Sub-região & Precipitação pluvial & Erosividade \\
\hline & $\mathrm{mm} \mathrm{ano} \mathrm{Cu}^{-1}$ & $\mathrm{MJ} \mathrm{ma} \mathrm{h}^{-1} \mathrm{~h}^{-1} \mathrm{ano}^{-1}$ \\
Alfié & $1.411,00$ & 8.243 \\
Cataquinho & $1.580,90$ & 13.018 \\
Cocais & $1.545,40$ & 9.191 \\
Coqueiro & $1.757,70$ & 12.046 \\
Cordeiros & $1.563,30$ & 13.584 \\
Fábrica & $1.878,90$ & 26.676 \\
Gaspar & $1.681,40$ & 11.042 \\
Lagoa Grande & $1.377,60$ & 8.397 \\
Rubro Negro & $1.284,10$ & 14.019 \\
Média & $1.564,50$ & 12.913 \\
\hline
\end{tabular}


Tabela 3 - Distribuição dos valores mensais de precipitação pluvial e erosividade no ano de 2005, em nove sub-regiões, na região do Vale do Rio Doce, MG.

\begin{tabular}{|c|c|c|c|c|c|c|c|c|c|}
\hline \multirow[b]{2}{*}{ Meses } & \multicolumn{9}{|c|}{ Sub-regiões } \\
\hline & $\mathrm{R} 1$ & $\mathrm{R} 2$ & R3 & $\mathrm{R} 4$ & R5 & R6 & R7 & $\mathrm{R} 8$ & R9 \\
\hline & \multicolumn{9}{|c|}{ Precipitação Pluvial } \\
\hline & & & & & $\mathrm{nm}$ ano & 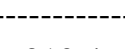 & & & \\
\hline Jan. & 286,3 & 364,8 & 284,2 & 293,6 & 316,2 & 310,4 & 246,6 & 363,5 & 300,7 \\
\hline Fev. & 182,9 & 181,6 & 157,5 & 207,0 & 210,1 & 522,0 & 204,7 & 186,9 & 16,0 \\
\hline Mar. & 290,1 & 223,3 & 365,5 & 402,3 & 193,0 & 170,4 & 316,5 & 159,8 & 5,3 \\
\hline Abr. & 25,4 & 75,5 & 50,3 & 47,2 & 51,3 & 74,4 & 19,1 & 37,3 & 72,6 \\
\hline Mai. & 39,1 & 24,6 & 25,4 & 39,4 & 64,0 & 68,1 & 61,0 & 30,2 & 56,4 \\
\hline Jun. & 32,8 & 41,9 & 17,8 & 8,1 & 35,8 & 25,7 & 32,0 & 15,5 & 58,9 \\
\hline Jul. & 1,0 & 27,7 & 9,7 & 10,4 & 2,0 & 3,3 & 9,4 & 6,6 & 12,7 \\
\hline Ago. & 3,8 & 17,3 & 3,6 & 3,6 & 22,4 & 8,4 & 6,4 & 9,1 & 17,3 \\
\hline Set. & 72,6 & 35,8 & 87,1 & 51,8 & 65,1 & 59,7 & 112,8 & 26,7 & 62,7 \\
\hline Out. & 50,8 & 91,4 & 30,7 & 68,1 & 47,0 & 40,4 & 57,66 & 77,7 & 64,3 \\
\hline Nov. & 256,5 & 257,8 & 254,0 & 296,2 & 271,7 & 281,9 & 325,1 & 250,2 & 300,2 \\
\hline Dez. & 169,7 & 239,3 & 259,6 & 330,0 & 284,7 & 314,2 & 290,1 & 214,1 & 317,0 \\
\hline \multirow[t]{3}{*}{ Total } & $1.411,0$ & $1.581,0$ & $1.545,4$ & $1.757,7$ & $1.563,3$ & $1.878,9$ & $1.681,4$ & $1.377,6$ & $1.284,1$ \\
\hline & \multicolumn{9}{|c|}{ Erosividade } \\
\hline & & & & ----- 1 & $\mathrm{~nm} \mathrm{ha}{ }^{-1}$ & $\mathrm{ano}^{-1}$---- & & & \\
\hline Jan. & 3.432 & 3.589 & 2.636 & 2.790 & 3.390 & 3.041 & 1.859 & 4.330 & 6.594 \\
\hline Fev. & 1.887 & 1.833 & 1.099 & 1.172 & 3.485 & 16.357 & 1.853 & 1.635 & 27 \\
\hline Mar. & 474 & 2.123 & 2.573 & 3.816 & 507 & 192 & 1.867 & 560 & 0 \\
\hline Abr. & 38 & 1.745 & 50 & 117 & 94 & 358 & 6 & 81 & 879 \\
\hline Mai. & 117 & 3 & 3 & 351 & 707 & 828 & 385 & 150 & 110 \\
\hline Jun. & 124 & 14 & 6 & 0 & 385 & 67 & 133 & 0 & 145 \\
\hline Jul. & 0 & 0 & 0 & 0 & 0 & 0 & 29 & 0 & 0 \\
\hline Ago. & 6 & 3 & 0 & 0 & 214 & 48 & 8 & 3 & 4 \\
\hline Set. & 203 & 128 & 415 & 448 & 339 & 411 & 728 & 47 & 62 \\
\hline Out. & 215 & 1.027 & 33 & 331 & 242 & 213 & 480 & 427 & 257 \\
\hline Nov. & 1.102 & 1.462 & 1.125 & 1.412 & 1.132 & 1.024 & 2.122 & 685 & 833 \\
\hline Dez. & 645 & 1.091 & 1.251 & 1.609 & 3.089 & 4.137 & 1.572 & 479 & 5.108 \\
\hline Total & 8.243 & 13.018 & 9.191 & 12.046 & 13.584 & 26.676 & 11.042 & 8.397 & 14.019 \\
\hline
\end{tabular}

R1: Alfié; R2: Cataquinho; R3: Cocais; R4: Coqueiro; R5: Cordeiros; R6: Fábrica; R7: Gaspar; R8: Lagoa Grande; R9: Rubro Negro.

Os valores do tempo de retorno, determinados para os menores índices de erosividade anual observados para Ferros (5.508 MJ mm ha $\mathrm{M} \mathrm{h}^{-1}$ ano $^{-1}$ ) e Guanhães (5.542 MJ mm $\mathrm{ha}^{-1} \mathrm{~h}^{-1}$ ano $\left.^{-1}\right)$ foram de um ano. Para os maiores índices, 19.632 e $22.931 \mathrm{MJ} \mathrm{mm} \mathrm{ha}^{-1} \mathrm{~h}^{-1}$ ano $^{-1}$, foram de 150 anos. Portanto, é esperado ocorrer, nestes locais, um valor do índice anual de erosividade igual ou superior a $19.632 \mathrm{MJ} \mathrm{mm} \mathrm{ha}^{-1} \mathrm{~h}^{-1} \mathrm{ano}^{-1}$ para Ferros e $22.931 \mathrm{MJ} \mathrm{mm} \mathrm{ha}^{-1} \mathrm{~h}^{-1} \mathrm{ano}^{-1}$, para Guanhães, pelo menos uma vez a cada 150 anos. Roque et al. (2001) obtiveram índices de erosividade anual, esperados para diferentes tempos de retorno, verificando para 100 anos, valores de 14.292 $\mathrm{MJ} \mathrm{mm} \mathrm{ha}^{-1} \mathrm{~h}^{-1}$ ano $^{-1}$. Dias \& Silva (2003) observaram, para um tempo de retorno de 50 anos, valor de erosividade anual de $5.950 \mathrm{MJ} \mathrm{mm} \mathrm{ha}^{-1} \mathrm{~h}^{-1}$ ano $^{-1}$, enquanto Martins (2005) constatou, para uma erosividade de $11.858 \mathrm{MJ}$ $\mathrm{mm} \mathrm{ha}^{-1} \mathrm{~h}^{-1}$ ano $^{-1}$, um tempo de retorno de 215,4 anos. 
Tabela 4 - Tempo de retorno (TR) dos valores dos índices mensais e anuais de erosividade EI $_{30}$ de Ferros e Guanhães, MG, durante o período de 1969 a 2005.

\begin{tabular}{|c|c|c|c|c|c|c|c|c|c|c|c|c|c|}
\hline \multirow[t]{2}{*}{ TR } & \multicolumn{12}{|c|}{ Mês } & \multirow[t]{2}{*}{ Anual } \\
\hline & Jan. & Fev. & Mar. & Abr. & Mai. & Jun. & Jul. & Ago. & Set. & Out. & Nov. & Dez. & \\
\hline \multirow[t]{2}{*}{ Anos } & ------ & & 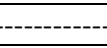 & & 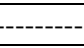 & $\mathrm{MJ} \mathrm{mm}$ & $\mathrm{a}^{-1} \mathrm{~h}^{-1} \mathrm{pe}$ & íodo $^{-1}-$ & - & 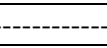 & -- & -- & - \\
\hline & \multicolumn{13}{|c|}{ Ferros } \\
\hline 1 & 12 & 1 & 3 & 0 & 0 & 0 & $*$ & 0 & 0 & 1 & $*$ & $*$ & 5.508 \\
\hline 1,1 & 321 & 73 & 114 & 14 & 5 & 0 & $*$ & 0 & 2 & 51 & $*$ & $*$ & 9.277 \\
\hline 1,2 & 508 & 130 & 192 & 29 & 9 & 1 & $*$ & 1 & 4 & 90 & $*$ & $*$ & 9.977 \\
\hline 1,5 & 991 & 303 & 414 & 77 & 23 & 3 & $*$ & 3 & 17 & 206 & $*$ & $*$ & 11.096 \\
\hline 2 & 1.687 & 596 & 763 & 171 & 47 & 7 & $*$ & 8 & 50 & 397 & $*$ & $*$ & 12.075 \\
\hline 3 & 2.872 & 1.172 & 1.406 & 378 & 97 & 20 & $*$ & 21 & 148 & 765 & $*$ & $*$ & 13.142 \\
\hline 4 & 3.914 & 1.737 & 2.005 & 600 & 148 & 37 & $*$ & 38 & 278 & 1.121 & $*$ & $*$ & 13.804 \\
\hline 5 & 4.771 & 2.233 & 2.517 & 806 & 193 & 53 & $*$ & 55 & 417 & 1.431 & $*$ & $*$ & 14.246 \\
\hline 10 & 8.224 & 4.459 & 4.702 & 1.816 & 405 & 150 & $*$ & 149 & 1.271 & 2.801 & $*$ & $*$ & 15.534 \\
\hline 30 & 16.245 & 10.583 & 10.271 & 5.013 & 1.022 & 545 & $*$ & 524 & 5.112 & 6.487 & $*$ & $*$ & 17.309 \\
\hline 50 & 21.594 & 15.191 & 14.239 & 7.664 & 1.505 & 935 & $*$ & 886 & 9.150 & 9.217 & $*$ & $*$ & 18.110 \\
\hline 100 & 30.161 & 23.221 & 20.895 & 12.616 & 2.370 & 1.763 & $*$ & 1.642 & 18.123 & 13.919 & $*$ & $*$ & 19.099 \\
\hline \multirow[t]{2}{*}{150} & 35.867 & 28.935 & 25.492 & 16.336 & 3.000 & 2.540 & $*$ & 2.261 & 25.829 & 17.236 & $*$ & $*$ & 19.632 \\
\hline & \multicolumn{13}{|c|}{ Guanhães } \\
\hline 1 & 5 & 8 & 2 & 1 & 0 & 0 & 0 & 0 & 0 & 4 & 3 & $*$ & 5.542 \\
\hline 1,1 & 217 & 156 & 112 & 38 & 3 & 0 & 0 & 0 & 2 & 107 & 188 & $*$ & 9.924 \\
\hline 1,2 & 370 & 236 & 195 & 63 & 6 & 1 & 1 & 1 & 4 & 172 & 343 & $*$ & 10.765 \\
\hline 1,5 & 805 & 433 & 434 & 131 & 16 & 3 & 3 & 2 & 16 & 345 & 828 & $*$ & 12.121 \\
\hline 2 & 1.496 & 703 & 822 & 235 & 37 & 8 & 7 & 6 & 46 & 599 & 1.668 & $*$ & 13.323 \\
\hline 3 & 2.779 & 1.141 & 1.558 & 423 & 82 & 21 & 20 & 18 & 130 & 1.042 & 3.360 & $*$ & 14.644 \\
\hline 4 & 3.983 & 1.512 & 2.258 & 595 & 132 & 37 & 34 & 34 & 238 & 1.436 & 5.050 & $*$ & 15.471 \\
\hline 5 & 5.016 & 1.811 & 2.864 & 740 & 178 & 54 & 49 & 51 & 351 & 1.764 & 6.554 & $*$ & 16.025 \\
\hline 10 & 9.452 & 2.971 & 5.506 & 1.350 & 406 & 152 & 132 & 154 & 1.016 & 3.107 & 13.423 & $*$ & 17.653 \\
\hline 30 & 20.872 & 5.519 & 12.465 & 2.862 & 1.138 & 553 & 453 & 607 & 3.837 & 6.302 & 32.888 & $*$ & 19.921 \\
\hline 50 & 29.069 & 7.150 & 17.541 & 3.918 & 1.752 & 948 & 759 & 1.078 & 6.689 & 8.470 & 47.840 & $*$ & 20.954 \\
\hline 100 & 42.886 & 9.690 & 26.197 & 5.665 & 2.908 & 1.784 & 1.392 & 2.116 & 12.844 & 11.986 & 74.277 & $*$ & 22.236 \\
\hline 150 & 52.467 & 11.344 & 32.253 & 6.858 & 3.782 & 2.477 & 1.905 & 3.001 & 18.014 & 14.349 & 93.308 & $*$ & 22.931 \\
\hline
\end{tabular}

* Valores que não apresentaram adequabilidade.

\section{CONCLUSÕES}

Os meses considerados mais críticos em relação à erosão hídrica, em razão da ocorrência de chuvas, são de novembro a março, para as sub-regiões estudadas do Vale do Rio Doce, MG.

A erosividade média anual das chuvas foi de 12.912 $\mathrm{MJ} \mathrm{mm} \mathrm{ha}^{-1} \mathrm{~h}^{-1} \mathrm{ano}^{-1}$, sendo classificada como muito alta. Da mesma forma, entre as sub-regiões, as erosividades foram consideradas muito altas no período de estudo.

A erosividade anual de Ferros e Guanhães para os tempos de retorno foi consideradas alta a muito alta. Em média, os valores mensais de erosividade para os meses de novembro a março são considerados críticos.

\section{AGRADECIMENTOS}

A CENIBRA S. A. e ao pesquisador Dr. Fernando Palha Leite, pelo apoio e concessão dos dados de precipitação.

\section{REFERÊNCIAS BIBLIOGRÁFICAS}

AQUINO, R.F. Padrões de chuvas e variabilidade espacial da erosividade para o Sul do Estado de Minas Gerais. 2005. 90p. Dissertação (Mestrado em Solos e Nutrição de Plantas)-Universidade Federal de Lavras, Lavras, 2005.

BERTOL, I. Avaliação da erosividade da chuva na localidade de Campos Novos (SC) no período de 19811990. Pesquisa Agropecuária Brasileira, Brasília, v.29, n.9, p.1453-1458, set. 1994. 
BERTOL, I. Índice de erosividade $\left(\mathrm{EI}_{30}\right)$ para Lages (SC): $1^{a}$ aproximação. Pesquisa Agropecuária Brasileira, Brasília, v.28, n.4, p.515-521, abr. 1993.

\section{BERTONI, J.; LOMBARDI NETO, F. Conservação do} solo. São Paulo: Ícone, 2005. 355p.

CARVALHO, R.; SILVA, M. L. N. ; AVANZI, J. C.; CURI, N.; SOUZA, F. S. de. Erosão hídrica em latossolo vermelho sob diversos sistemas de manejo do cafeeiro no sul de Minas Gerais. Ciência e Agrotecnologia, Lavras, v.31, n.6, p.1679-1687, nov./dez., 2007.

\section{CARVALHO, M.P.; LOMBARDI NETO, F.; VASQUES}

FILHO, J.; CATANEO, A. Erosividade da chuva de Mococa (SP) analisada pelo índice EI30. Revista Brasileira de Ciência do Solo, Campinas, v.13, n.2, p.243-249, maio/ago. 1989.

CELULOSE NIPO BRASILEIRA S.A. Levantamento semidetalhado de solos das regiões do Rio Doce, Cocais, Sabinópolis e Virginópolis. Ipatinga, 2001. v.1, 101p.

CELULOSE NIPO BRASILEIRA S.A. Sistema de monitoramento climático cenibra. Ipatinga, 2004. 10p.

CHOW, V.T. The log-probability law and its engineering applications. Proceedings ASCE, New York, v.80, n.536, 1954.

COGO, N.P. Conceitos e princípios envolvidos no manejo de solo para fins de controle da erosão hídrica. In: CONGRESSO BRASILEIRO DE CIÊNCIA DO SOLO, 21., 1988, Campinas, SP. Anais... Campinas: Sociedade Brasileira de Ciência do Solo, 1988. p.251-262.

DEDECEK, R.A. Fatores de erosividade da chuva, enxurrada e perdas de solo sob condições de cerrado. Pesquisa Agropecuária Brasileira, Brasília, v.23, n.12, p.1431-1438, dez. 1988.

DIAS, A.S.; SILVA, J.R.C. A erosividade das chuvas em Fortaleza (CE): I., distribuição, probabilidade de ocorrência e período de retorno: $1^{\mathrm{a}}$ aproximação. Revista Brasileira de Ciência do Solo, Viçosa, v.27, n.2, p.335345, mar./abr. 2003.

FOSTER, G.R.; McCOOL, D.K.; RENARD, K.G.; MOLDENHAUER, W.C. Conversion of the universal soil loss equation to SI metric units. Journal of Soil and
Water Conservation, Ankeny, v.36, n.6, p.355-359, Nov./ Dec. 1981.

FOURNIER, F. The effect of climatic factors on soil erosion estimates of solids transported in suspension in runoff. [S.1.]: Association Hydrologic Int. Public, 1956. 6p.

FREITAS, A.J. et al. Equações de chuvas intensas no estado de Minas Gerais. Belo Horizonte: Companhia de Saneamento de Minas Gerais; Viçosa, MG: UFV, 2001. 65p.

HAAN, C.T. Statistical methods in hydrology. 2.ed. Ames: The Iowa State University, 1979. 377p.

HUDSON, N. Soil conservation. 2.ed. Ithaca: Cornell University, 1971. 320p.

JUNQUEIRA JÚNIOR, J. A.; GOMES, N. M.; MELLO, C. R. de; SILVA, A. M. da. Precipitação provável para a região de Madre de Deus, Alto Rio Grande: modelos de probabilidades e valores característicos. Ciência e Agrotecnologia, Lavras, v.31, n.3, p.842-850, maio, jun., 2007.

LAL, R. Soil erosion on Alfisoils in Western Nigeria: III., effects of rainfall characteristics. Geoderma, Amsterdam, v.16, n.5, p.389-401, 1976.

LAL, R. Erodibility and erosivity. In: Soil erosion research methods. Ankeny: SWCS, 1988. p.141-160.

LOMBARDI NETO, F. Dimensionamento de terraço. In: SIMPÓSIO SOBRE TERRACEAMENTO AGRÍCOLA, 1988, Campinas, SP. Anais... Campinas: Fundação Cargill, 1989. p.26-59.

LOMBARDI NETO, R. Rainfall erosivity: its distribution and relationship with soil loss at Campinas, Brasil. 1977. 53p. Dissertação (Mestrado)-Purdue University, West Lafayette.

LOPES, P.R.C.; BRITO, L.T.L. Erosividade da chuva no médio São Francisco. Revista Brasileira de Ciência do Solo, Campinas, v.17, n.1, p.129-133, jan./abr. 1993.

MARIA, I.C. de. Cálculo da erosividade da chuva. In: INSTITUTO AGRONÔMICO DE CAMPINAS. Manual de programas de processamento de dados de campo e de laboratório para fins de experimentação em conservação do solo. Campinas, 1994. 
MARQUES, J.J.G.S.M.; ALVARENGA, R.C.; CURI, N. Erosividade das chuvas de Sete Lagoas, MG. Pesquisa Agropecuária Brasileira, Brasília, v.33, n.5, p.285-288, maio 1998.

MARTINS, S.G. Erosão hídrica em povoamento de eucalipto sobre solos coesos nos Tabuleiros Costeiros, ES. 2005. 106p. Tese (Doutorado)-Universidade Federal de Lavras, Lavras, 2005.

MORETI, D.; CARVALHO, M.P.; MANNIGEL, A.R.; MEDEIROS, L.R. Importantes características de chuva para a conservação do solo e da água no município de São Miguel (SP). Revista Brasileira de Ciência do Solo, Viçosa, v.27, n.4, p.713-725, jul./ago. 2003.

RIBEIRO, B. T.; AVANZI, J. C.; MELLO, C. R. de; LIMA, J. M. de; SILVA, M. L. N.; Comparação de distribuições de probabilidade e estimativa da precipitação provável para a região de Barbacena, MG. Ciência e

Agrotecnologia, Lavras, v.31, n.5, p.1297-1302, set./out. 2007.

ROQUE, C.G.; CARVALHO, M.P.; PRADO, R.M. Fator erosividade da chuva de Piraju (SP): distribuição, probabilidade de ocorrência, período de retorno e correlação com o coeficiente da chuva. Revista Brasileira de Ciência do Solo, Viçosa, v.25, n.1, p.147156, jan./mar. 2001.
SCHWAB, G.O.; FREVERT, R.K.; DMINSTER, T.W.; BARNES, K.K. Soil and water conservation engineering. 2.ed. New York: J.Wiley, 1966. 683p. (The Fergunson Foundation Agricultural Engineering Series).

SILVA, A.M. Rainfall erosivity map for Brazil. Catena, Amsterdam, v.57, n.3, p.251-259, Aug. 2004.

SILVA, J.R.C.; DIAS, A.S. A erosividade das chuvas em Fortaleza (CE): II., correlação com o coeficiente de chuva e atualização do fator R no período de 1962 a 2000.

Revista Brasileira de Ciência do Solo, Viçosa, v.27, n.2, p.347-354, abr./jun. 2003.

SILVA, M.L.N.; FREITAS, P.L.; BLANCANEAUX, P.; CURI, N. Índices de erosividade das chuvas da região de Goiânia (GO). Pesquisa Agropecuária Brasileira, Brasília, v.32, n.10, p.977-985, out. 1997.

VAL, L.A.; BAHIA, V.G.; FREIRE, J.C.; DIAS JÚNIOR, M.S. Erosividade das chuvas em Lavras - MG.

Ciência e Prática, Lavras, v.10, n.2, p.199-209, jul./dez. 1986.

WISCHMEIER, W.H.; SMITH, D.D. Rainfall energy and its relationships to soil loss. Transactions of the

American Geophysical Union, Washington, v.39, n.2, p.285-291, 1958. 